\title{
Influence of scarification method on seed germination of the terrestrial orchid Anacamptis laxiflora (Lam.)
}

\author{
Gwenaëlle Deconninck ${ }^{1, *}$, Argyrios Gerakis ${ }^{2}$
}

\begin{abstract}
A critical step during in vitro sexual propagation of terrestrial orchids is the treatment of the microscopic seeds with a disinfecting solution that kills bacteria and fungi attached to the seeds. This treatment is necessary to prevent infection of the culture vessels. At the same time, the treatment serves to scarify the seeds, a process that disrupts seed dormancy and initiates germination. The literature is inconclusive with respect to the proper combination of disinfecting solution strength and treatment duration. Both factors should be adapted to each species to guarantee minimal infection rate without damaging the embryo. This research aims to compare three disinfection/scarification methods for seeds of Anacamptis laxiflora (Lam.): (i) soaking in $0.5 \% \mathrm{NaClO}$, (ii) soaking in $0.5 \% \mathrm{NaClO}$, then centrifugation, and (iii) presoaking the seeds in sucrose solution, then soaking in $0.5 \% \mathrm{NaClO}$. The seeds were soaked in the disinfecting solution for 5 to $85 \mathrm{~min}$. Following scarification, the seeds were sown in modified Malmgren nutrient medium. Infected and germinated vessels were counted at 41 and $189 \mathrm{~d}$ after sowing. We found that the longer the chemical treatment, the lower the infection rate, and the higher the germination rate. There was no significant difference in germination rate between the $\mathrm{NaClO}$ and the $\mathrm{NaClO}$-plus-centrifugation method; in fact, the slight savings in disinfection time effected by centrifugation were more than offset by the added complexity of the method. Moreover, we found that centrifugation significantly delays germination. The sucrose presoak-plus- $\mathrm{NaClO}$ method was superior to plain $\mathrm{NaClO}$, as the sucrose stimulates the germination of microbial spores on the surface of the seeds, making them easier to kill. Perhaps seeds with thicker testa as well as whole immature capsules could benefit even more from the pretreatment in sucrose solution.
\end{abstract}

Keywords: centrifugation; disinfection; in vitro propagation; Orchidaceae; scarification.

${ }^{1}$ Faculty of Science and Technology, La Rochelle University, France. ORCID: 00000003-2002-0992

${ }^{2}$ Department of Food Science and Technology, Ionian University, Greece. ORCID: 0000-0002-6927-1357

* Corresponding author's contact information:

5 venelle de la petite grange, 17590 Ars-enré, France, e-mail: gwen.02100@hotmail.fr, tel.: +33658785633

DOI: $10.2478 /$ ebtj-2021-0004

(C) 2021 Authors. This work was licensed under the Creative Commons AttributionNonCommercial-NoDerivs 4.0 License.

\section{Introduction}

The Orchidaceae is one of the most diverse and widespread family of flowering plants (1). About 750 genera including more than 25,000 species are currently accepted (2). Nowadays, terrestrial orchids are confronted with several threats. Climate change happens so fast that species cannot adapt (2-4); illicit collection for commercial uses depletes natural populations (5-7); habitats are being lost or degraded to human activity including urbanization, cultivation, grazing, and pollution $(8,9)$. These threats accelerate the disappearance of many orchid species and contribute to a global disequilibrium of biodiversity (3). In vitro propagation is a promising method to protect and conserve threatened orchid species with multiple benefits (10). It is helpful to propose a protocol that can be adopted by plant propagation laboratories and professionals for the mass production of seedlings for use in conservation and restoration programs.

A crucial step during the in vitro sexual propagation of orchids is the treatment of the microscopic seeds with a disinfecting solution. The purpose of disinfection is to kill bacteria and fungi attached to the seed surface that may infect the culture vessels. The same treatment serves to achieve chemical scarification, a process that disrupts seed dormancy and initiates germination (11). The common technique used to scarify orchids seeds is agitation in disinfecting solution (12). However, the literature is inconclusive with respect to the proper composition of the solution, its concentration, or the duration of soaking. 
Many practitioners use ethanol (13) or sodium hypochlorite (14). The duration of the disinfection depends on the concentration of the solution. An overly short disinfection will fail to kill all microbes, whereas an overly long disinfection may damage the embryo $(13,14)$. The decision is further complicated by the fact that different species have seed coats (testas) of different thickness, necessitating different treatment durations. If terrestrial orchid propagation is ever attempted at a mass scale for commercial or conservation purposes, optimal treatment duration must be determined for each species.

The agitation of seeds is usually conducted within test tubes. Some practitioners have modified the standard technique; Jevšnik and Luthar (12) obtained germination percentage rates between 60 and $90 \%$ by centrifuging the seeds after disinfection in microcentrifuge tubes. Ponert et al. (13) used a syringe to mix the seeds with the disinfection solution and obtained good results also. Some authors $(12,15,16)$ report a method called presoaking, whereby the seeds are pretreated in a sucrose or honey solution before being disinfected.

Svante Malmgren is a veteran practitioner who has propagated more than 200 terrestrial species of orchids and orchid hybrids in vitro $(17,18)$. He advocates that treatment duration as well as solution concentration must be determined for each species. His method is straightforward, although somewhat subjective; he recommends soaking the seeds in $0.3-1 \% \mathrm{Na}$ $\mathrm{ClO}$ solution for 5-45 min, and terminates disinfection when most seeds have been bleached. However, the endpoint may be judged differently by different people.

Previous studies $(10,19)$ attempted to determine the optimal disinfection time for two terrestrial species, Anacamptis laxiflora (Lam.) R.M.Bateman, Pridgeon \& M.W.Chase with thin testa and Himantoglossum robertianum (Loisel.) P.Delforge with thick testa. They realized that a $1 \% \mathrm{NaClO}$ solution may be too strong to precisely control the disinfection time for seeds with permeable testas such as those of $A$. laxiflora (19). Instead, a weaker solution of $\mathrm{NaClO}$ with a $0.5 \%$ concentration and a range of times from 5 to $85 \mathrm{~min}$ allows for more precise control (10).

The aim of this study was to test three disinfection/scarification methods on seeds of $A$. laxiflora and compare disinfection and germination rates. We aimed to use the $\mathrm{NaClO}$ soaking method popularized by Svante Malmgren as a reference, then compare it to the $\mathrm{NaClO}$-plus-centrifugation method proposed by Jevšnik and Luthar, and the sucrose presoak-plus- $\mathrm{NaClO}$ variation advocated by several practitioners.

\section{Material and Methods}

\subsection{Experimental setup}

To test the influence of the disinfection method (that also serves as scarification) on seed disinfection and germination, combinations of three methods and nine durations $(5,15,25,35,45$, $55,65,75$, and $85 \mathrm{~min}$ ) were tested on seeds of Anacamptis laxiflora. The three disinfection/scarification methods to be described in detail are abbreviated as follows: (1) $\mathrm{NaClO}$ (soaking in $\mathrm{NaClO}$ solution), (2) CENTRIFUGE (soaking in $\mathrm{NaClO}$ solution, then centrifugation), and (3) PRESOAK (presoaking seeds in sucrose solution, then soaking in $\mathrm{NaClO}$ solution).

Each experimental treatment consisted of one duration and one disinfection/scarification method. Each experimental run consisted of 16 culture vessels per treatment that served as experimental replications plus four "blanks", i.e. culture vessels without seeds. The blanks were subject to the same treatment as the vessels with seeds, including simulated sowing with imaginary seeds. The purpose of the blanks was to reveal possible shortcomings of our sowing technique that were not due to seed-borne contaminants.

\subsection{Seeds}

Mature seeds were collected in May 2018 on the island of Cephalonia, Greece. Anacamptis laxiflora has a localized distribution in Cephalonia, yet usually is abundant in its stations (20), so that seed collection did not jeopardize the natural populations. Foreign material, such as capsule fragments, was removed by sieving through a $500 \mu \mathrm{m}$ sieve. The seeds were dried in a desiccator with silica gel, sealed in labelled glass vials and stored at $-20^{\circ} \mathrm{C}$ until sowing.

\subsection{Preparation of the solutions 2.3.1 Nutrient medium}

Because orchid seeds are microscopic and lack endosperm, they establish an association with symbiotic fungi called mycorrhiza (21). In nature, this association is necessary for germination as it supplies nutrients to the seeds, including C. Reproducing the mycorrhizal association in the laboratory is possible (11). However, because it adds complexity, many practitioners opt to supply the nutrients via a sterile nutrient medium. Numerous recipes exist for nutrient media for terrestrial orchid propagation (11). Because the majority of terrestrial plants require the same nutrients for growth and development (22), most recipes share a few base ingredients in various proportions.

In this study, a modified version of "SM-organic" medium was used, a time-tested formula by veteran practitioner Svante Malgrem published by Rasmussen (11). The term "organic" refers to the $\mathrm{N}$ source, an amino acid mixture sold under the trade name Vaminolac ${ }^{\oplus}$ (Fresenius Kabi, Uppsala, Sweden). In Greece, $\operatorname{Vaminolac}^{\circledR}$ cannot be sold without prescription as it is considered a medicine. Therefore, it was substituted by Amina-Fe (Humofert, Metamorfosi, Greece), a liquid fertilizer containing amino acids and chelate Fe. Because Amina-Fe more than covers the Fe requirement in Malgrem's recipe, the Fe salt was omitted. Further, $\mathrm{Ca}_{3}\left(\mathrm{PO}_{4}\right)_{2}$ was replaced by $\mathrm{CaHPO}_{4}$. The use of Danish agar necessitated increasing the amount from the original recipe to achieve proper gelling. The formula is listed in Table 1. After mixing, $\mathrm{pH}$ was adjusted to 5.5-6.0 with a few drops of $0.1 \mathrm{M} \mathrm{H}_{2} \mathrm{SO}_{4}$ solution. Finally, the medium was transferred to a $1 \mathrm{~L}$ volumetric flask and stored in a plastic bottle at $4^{\circ} \mathrm{C}$.

\subsubsection{Disinfecting solution}

A commercial formulation of household bleach (Klinex ${ }^{\oplus}$, Uni- 
Table 1. Formula for modified "SM-organic" nutrient medium

\begin{tabular}{|c|c|}
\hline Ingredients & Quantity \\
\hline Bottled water to make & $1 \mathrm{~L}$ \\
\hline $\mathrm{CaHPO}_{4}$ & $99 \mathrm{mg}^{\mathrm{b}}$ \\
\hline $\mathrm{KH}_{2} \mathrm{PO}_{4}$ & $75 \mathrm{mg}$ \\
\hline $\mathrm{MgSO}_{4} \cdot 7 \mathrm{H}_{2} \mathrm{O}$ & $75 \mathrm{mg}$ \\
\hline Soluvit $^{\circ} \mathrm{c}$ & $10 \mathrm{~mL}$ \\
\hline Amina-Fe $^{\mathrm{d}}$ & $0.92 \mathrm{~mL}$ \\
\hline Kinetin & $5 \mathrm{mg}$ \\
\hline Saccharose (sucrose $)$ & $10 \mathrm{~g}$ \\
\hline Activated charcoal & $1 \mathrm{~g}$ \\
\hline Danish agar & $12 \mathrm{~g}$ \\
\hline Pineapple juice $^{\mathrm{e}}$ & $25 \mathrm{~mL}$ \\
\hline $0.1 \mathrm{M} \mathrm{H}_{2} \mathrm{SO}_{4}$ for pH adjust- & $15-20 \mathrm{drops}$ \\
\hline ment & $1 \mathrm{~cm}^{3}$ per culture vessel \\
\hline Potato (Solanum tuberosum $)$ & tuber
\end{tabular}

${ }^{a}$ Vikos $^{\circledast}$ (Ioannina, Greece)

${ }^{\mathrm{b}}$ Equivalent to $75 \mathrm{mg} \mathrm{Ca}_{3}\left(\mathrm{PO}_{4}\right)_{2}$ in the original formula

${ }^{c}$ Fresenius Kabi, Uppsala, Sweden

${ }^{\mathrm{d}}$ Humofert, Metamorfosi, Greece

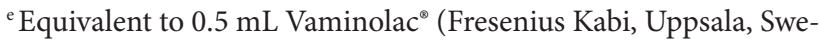
den) plus $10 \mathrm{mg} \mathrm{FeSO}_{4}$ in the original formula

lever, London), was used as stock solution. The nominal concentration of the commercial product $(4.8 \% \mathrm{w} / \mathrm{w})$ had been previously verified (10). The stock solution was diluted to $0.5 \%$. A drop of Tween ${ }^{\circledR} 20$ (Merck, Darmstadt, Germany) was added to reduce surface tension.

\subsubsection{Sucrose solution}

Presoaking the seeds in a sucrose solution was the initial step in the PRESOAK method. According to Hicks (16), sucrose encourages the growth of microorganisms, making them more susceptible to sterilization. There is little information whether the concentration of the solution has an effect. Some practitioners use a dilute solution, whereas others use up to $50 \%$ saturated solution. Hicks (16) prepared a solution by adding approximately the same amount of sucrose and seeds in his test tubes. For this study, a 10\% sucrose solution was used.

\subsection{Laboratory method}

\subsubsection{Preparation of materials}

The autoclavable materials (nutrient medium, potato cubes, polypropylene funnels, filter papers, Erlenmeyer flasks for draining the suspension, deionized water, beaker for disposing liquid waste, spatula, pair of pliers, absorbent paper) were wrapped in aluminum foil and sterilized in a Tuttnauer 2340 autoclave (Tuttnauer USA, Hauppauge, NY) programmed on a $30 \mathrm{~min}$ cycle (for cold departure) or $25 \mathrm{~min}$ cycle (for hot departure) at a temperature of $121^{\circ} \mathrm{C}$ and pressure of 1.2 bar.
The autoclavable materials were transferred to the laminar flow cabinet, except the nutrient medium that was taken out just before sowing to keep it warm. Working time to solidification of the medium was about $20 \mathrm{~min}$.

The interior surfaces of the laminar flow cabinet $\left(\mathrm{Esco}^{\circledR}\right.$ EQU/04-EBC-2A, Singapore) were disinfected with 70\% v/v ethanol. The non-autoclavable materials were disinfected with $70 \% \mathrm{v} / \mathrm{v}$ ethanol and placed in the cabinet: culture vessels (100 mL urine samplers made of polypropylene, individually wrapped in sterile packaging), $0.5 \% \mathrm{NaClO}$ solution, droppers, lighter, marker, pre-printed self-adhesive labels, alcohol burner, and two test tubes per treatment, one with seeds, one without. All materials were exposed to a germicidal UVC lamp for $50 \mathrm{~min}$. The workspace outside the cabinet was concurrently disinfected with a germicidal UVC lamp. Afterwards, the airflow in the cabinet was turned on for $15 \mathrm{~min}$ to purge airborne contaminants as per manufacturer's instructions $\left(\right.$ Esco $^{\circledR}$. Class II Type A/B3 Biohazard Safety Cabinets. User Operation Manual.). The sterile seal of the culture vessels was broken, and each was labelled with a pre-printed self-adhesive label.

\subsubsection{Seed Disinfection}

The seeds were disinfected in $15 \mathrm{~mL}^{\text {Sarstedt }}{ }^{\oplus}$ (Newton, NC, USA) polypropylene test tubes with conical base and screw cap as follows:

(i) $\mathrm{NaClO}$ : the first method consisted of scooping $60 \mathrm{mg}$ of seeds into the test tube and filling it nearly to the top with $0.5 \% \mathrm{NaClO}$ disinfecting solution. A second test tube serving as blank was filled only with disinfecting solution. Both tubes were capped and shaken vigorously a few times to remove any air bubbles in contact with the seeds. The shaking was repeated every 15 min thereafter till the end of the disinfection period. Afterwards, the suspensions were decanted into Erlenmeyer flasks fitted with a polypropylene funnel lined with filter paper to recover the seeds. The filter paper was soaked in the same disinfecting solution as the seeds. After filtering the suspensions, each filter paper was rinsed with seven $\mathrm{mL}$ of sterile deionized water using a dropper.

(ii) CENTRIFUGE: the second method was identical to the first, except two minutes before the end of the disinfecting period the tubes were placed in a SIGMA 3-16PK centrifuge (Osterode am Harz, Germany) for two minutes at 3,077 g (Gravitational acceleration units, not to be confused with grams.) and a temperature of $4^{\circ} \mathrm{C}$. The speed and the temperature of the centrifuge were configured according to Jevšnik and Luthar (12). After centrifugation, the supernatant was decanted into an empty beaker. Afterwards, the seeds were rinsed three times as follows: the tubes were filled with sterile deionized water nearly to the top and centrifuged using the same settings. The supernatant was decanted between rinses. Afterwards, the tube contents were emptied into an Erlenmeyer flask fitted with polypropylene funnel lined with filter paper to recover the seeds.

(iii) PRESOAK: six hours before disinfection, the tubes were filled with $10 \%$ sucrose solution nearly to the top, capped, and 
shaken vigorously to remove any air bubbles in contact with the seeds. At the end of the presoak, the suspensions were decanted into Erlenmeyer flasks fitted with a polypropylene funnel lined with filter paper to recover the seeds. After filtering the suspensions, the seeds were scraped from the filter paper with a spatula and transferred into one of the two clean test tubes (the other serving as blank). Thereafter, the same procedure as for the $\mathrm{NaClO}$ method was applied.

\subsubsection{Sowing}

Each culture vessel was filled with approximately $16 \mathrm{~mL}$ of sterile nutrient medium and a $1 \mathrm{~cm}$ potato cube, as potato has been shown beneficial to asymbiotic orchid propagation (23-25). The seeds were scraped with a spatula from the filter paper and distributed evenly within the culture vessels, approximately 4 $\mathrm{mg}$ of seed per vessel. The tips of the steel tools were heat sterilized with the alcohol burner between sowings. Afterwards, the vessels were incubated in a dark cabinet at an ambient temperature of $22^{\circ} \mathrm{C}$. At $41 \mathrm{~d}$ after the last sowing, all vessels were visually examined for the development of fungal and bacterial colonies. For consistency with earlier studies $(10,19)$, the vessels were examined again for germination at $189 \mathrm{~d}$ after the last sowing.

\subsection{Statistical methods}

The infection and germination probabilities were modelled based on the duration of soaking and the scarification method applied. The infection or germination variable (Y) is binary: a vessel is either infected or not; it germinates or not. The duration of soaking and the scarification method are continuous and categorical variables, respectively. Logistic regression can be used to characterize the relation between a dependent variable (necessarily taking the values 0 and 1 ) and one or more explanatory variables that can be categorical or continuous (2628). If the $\mathrm{NaClO}$ method is used as a reference, the probability of infection or germination is modeled as a function of three regressors (duration of soaking in $\mathrm{NaClO}$, plus two "dummy" or indicator variables representing the two alternative methods of scarification):

$$
\mathrm{P}\left(\mathrm{Y}=1 \mid \mathrm{X}_{1}, \mathrm{X}_{2}, \mathrm{X}_{3}\right)=1 /\left(1+\exp -\left(\beta_{0}+\beta_{1} \mathrm{X}_{1}+\beta_{2} \mathrm{X}_{2}+\right.\right.
$$$$
\left.\left.\beta_{3} X_{3}\right)\right) \quad \text { Eq. (1) }
$$

where $\mathrm{P}$ is probability, $\mathrm{Y}=$ nominal response, $\mathrm{X}_{1}, \mathrm{X}_{2}, \mathrm{X}_{3}=$ regressors, and $\beta_{0}, \beta_{1}, \beta_{2}, \beta_{3}=$ fitted parameters. The duration of soaking is $\mathrm{X}_{1}$. "Dummy" or indicator variables $\mathrm{X}_{2}, \mathrm{X}_{3}$ are defined in Table 2 . If $p$ denotes $\mathrm{P}(\mathrm{Y}=1)$, by algebraic transforma-

Table 2. Combinations of "dummy" or indicator variables that uniquely identify each scarification method for the purpose of logistic regression analysis. The $\mathrm{NaClO}$ method is specified as reference, in which case $\mathrm{X}_{2}=\mathrm{X}_{3}=0$

\begin{tabular}{|l|l|l|l|}
\hline Variable & $\mathrm{NaClO}$ & CENTRIFUGE & PRESOAK \\
\hline $\mathrm{X}_{2}$ & 0 & 1 & 0 \\
\hline $\mathrm{X}_{3}$ & 0 & 0 & 1 \\
\hline
\end{tabular}

tion of Eq. (1) we derive a function called the logit of $p$ or the $\log$ odds-ratio:

$$
\ln (p /(1-p))=\beta_{0}+\beta_{1} X_{1}+\beta_{2} X_{2}+\beta_{3} X_{3} \quad \text { Eq. (2) }
$$

Essentially, parameters $\beta_{2}, \beta_{3}$ represent the added probability of success (in terms of the log odds-ratio) when an alternative scarification method is used other than $\mathrm{NaClO}$.

The R programming language (29) was used to conduct the analysis. The level of significance for statistical tests was set a priori at $\alpha=0.05$.

\section{Results}

The infection rate for the 108 "blank" vessels was $1.9 \%$, which shows that our technique was valid and that nearly all contamination came from the seeds. As far as the vessels with seeds, we observed that all vessels that were not infected, germinated. This greatly simplified subsequent analysis, because once germination probability is modelled, the percent probability of infection can be estimated as 100 minus percent probability of germination. Ultimately, what matters most is the probability of germination, because it determines how many useable containers with seedlings are available for further culture.

\subsection{Duration}

Proportions of germinated vessels for each method are compared in Fig. 1. The fitted model is statistically significant. The statistical measures are in Table 3. Germinated seeds at $189 \mathrm{~d}$ after sowing are depicted in Fig. 2.

The equations that were used to model germination probabilities in Fig. 1 are derived from Eq. (1) substituting the parameter estimates from Table 3 . To model infection probabilities, the sign of the parameters can simply be reversed, i.e., they would be $\beta_{0}=3.8866, \beta_{1}=-0.1023, \beta_{2}=-0.1969$, and $\beta_{3}$ $=-0.9947$. From Fig. 1 it follows that the longer the chemical treatment, the lower the predicted infection rate and the higher the predicted germination rate. At $85 \mathrm{~min}$, the predicted infection rate approached zero for all methods and the predicted germination rate approached $100 \%$.

Infected and germinated vessels were counted at 41 and 189 d (Fig. 3). At $41 \mathrm{~d}$, there was not much difference in the proportion of germinated vessels between the $\mathrm{NaClO}$ and the PRESOAK method. On the contrary, the proportion of germinated vessels for the CENTRIFUGE method was substantially lower, meaning that centrifugation severely delayed germination.

\subsection{Scarification Method}

The results of the logistic regression highlight the absence of significant difference between the $\mathrm{NaClO}$ method that was used as a reference and the CENTRIFUGE method ( $p=0.587$ ); however, there is a significant difference between the $\mathrm{NaClO}$ and the PRESOAK method ( $p=0.008)$.

\section{Discussion}

\subsection{Duration}

With a weak $\mathrm{NaClO}$ solution (0.5\%) and disinfection/scarification times ranging from 5 to $85 \mathrm{~min}$, a good fit of the cumulative 
probability curve for germination of $A$. laxiflora seeds was obtained. Disinfection curves would be symmetrical, as any vessel that was not infected, germinated. The predicted germination rate asymptotically approaches $100 \%$ for each method tested, meaning that the range of times tested was adequate. In fact, extending the disinfection time beyond that range could damage the seed embryos (14,30,31). The Malmgren and Nyström (18) advice to soak terrestrial orchid seeds in $0.3-1 \% \mathrm{NaClO}$ solution for $5-45 \mathrm{~min}$ is only a general recommendation. On the other hand, Rasmussen's (11) recommendation of a $5 \% \mathrm{Na}$ $\mathrm{ClO}$ solution and a disinfection duration of up to several hours would almost certainly damage the seeds of $A$. laxiflora. The only way to predict optimal disinfection/scarification times for seeds of terrestrial orchids is to test each species individually. According to our study, using a duration up to $85 \mathrm{~min}$ is sufficient for seeds of species with a thin testa such as $A$. laxiflora. This time may have to be extended for seeds of species with a

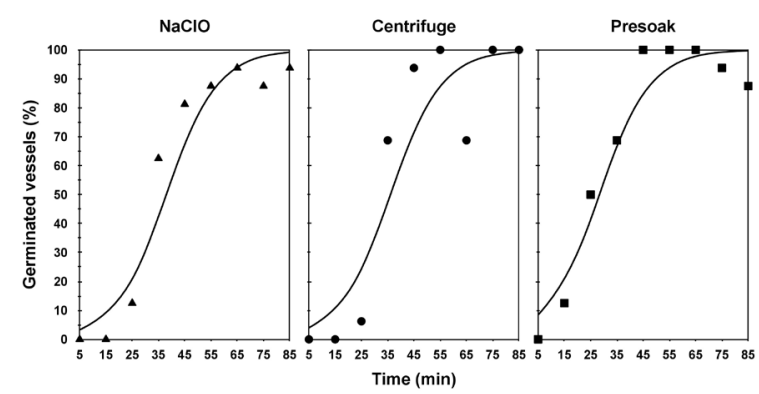

Figure 1. Effect of time and three disinfection-plus-scarification methods (NaClO, CENTRIFUGE, and PRESOAK) on the proportion of germinated vessels of Anacamptis laxiflora $189 \mathrm{~d}$ after sowing. Markers are measured points $(n=16)$ and lines are fitted models.

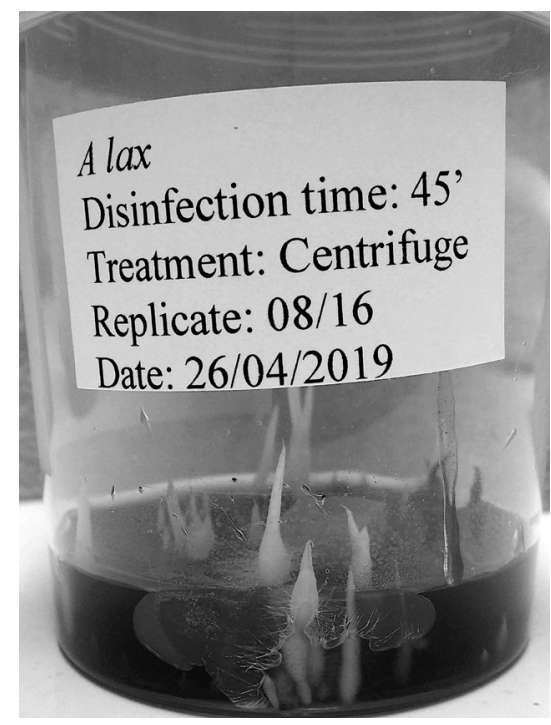

Figure 2. Germinated seeds of Anacamptis laxiflora $189 \mathrm{~d}$ after sowing

thicker testa such as Himantoglossum robertianum, as shown by Katsalirou et al. (19).

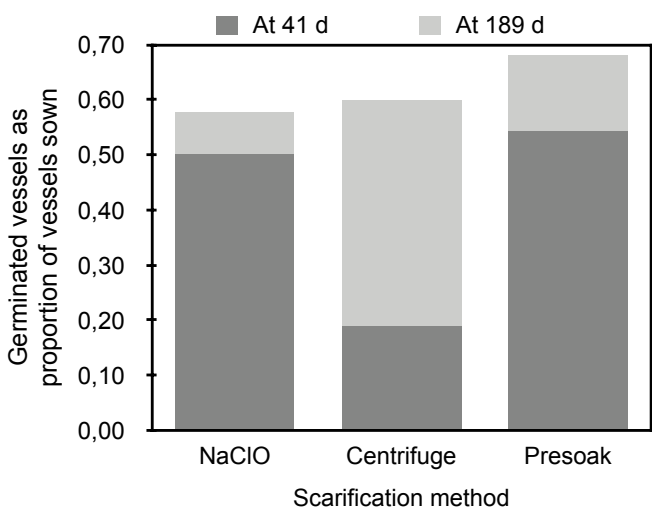

Figure 3. Effect of three disinfection-plus-scarification methods on the proportion of germinated vessels at 41 versus $189 \mathrm{~d}$. At $189 \mathrm{~d}$, the parameter estimates for the odds-ratios were not statistically significant for CENTRIFUGE $(p>|t|=0.720)$ and PRESOAK $(p>|t|=0.068)$ compared to the reference method, whereas at $41 \mathrm{~d}$ the parameter estimate was statistically significant for CENTRIFUGE $(p>|t|<0.001)$. Centrifugation seems to severely delay germination, although given enough time the proportion of germinated vessels catches up.

\subsection{Disinfection/scarification method 4.2.1 CENTRIFUGE method}

The parameter for the CENTRIFUGE method was not statistically significant (Table 3). Jevšnik and Luthar (12) had used this method to obtain $100 \%$ disinfection efficiency. They attributed their success to enhanced rehydration of the testa, and, by extension, the embryo, although this is more critical with older seeds (Tomaž Jevšnik, personal communication, 2019). We modified their technique using $15 \mathrm{~mL}$ test tubes versus microcentrifuge tubes and $0.5 \% \mathrm{NaClO}$ solution versus $16.6 \mathrm{~g} / \mathrm{L}$ of sodium dichlorocyanurate. Aside from those differences, Jevšnik and Luthar (12) worked on epiphytic orchid seeds and a single treatment duration of eight minutes. It may be possible that eight minutes is the optimal treatment duration for the species they were working on. It is not clear though whether they would have achieved the same results without centrifugation.

Generally, the germination period varies from a few weeks to several months according to species, culture media and the method used (32). We observed that germination of centrifuged seeds was severely delayed. At $41 \mathrm{~d}$, only $18.8 \%$ of sown vessels had germinated, as opposed to $50.0 \%$ for the $\mathrm{NaClO}$ and $54.2 \%$ for the PRESOAK methods (Fig. 3). Usually, seed germination is affected by three main environmental factors: temperature, light, and water (33). The centrifugation was performed at $4^{\circ} \mathrm{C}$. However, since the seeds had been stored at $-20^{\circ} \mathrm{C}$ for about a year, such a short exposure to cold would be irrelevant. Perhaps more importantly, the CENTRIFUGE treatment applied a gravitational force on the seeds. There is little information about the effect of increased gravitational force on germination. Most studies researching the impact of gravitational force on plants are old and focus on post-germination development $(34,35)$. However, in 1965, Siegel et al. studied 
the effect of gravitational force of $100 \mathrm{~g}$ (Gravitational acceleration units, not to be confused with grams.) for three days at $30^{\circ} \mathrm{C}$ on the germination of seeds of different species (36). Germination was inhibited compared to the control. Norris et al. (37) studied the effect of centrifugation on germination and seedling growth of oat (Avena sativa L.) seeds and confirmed that centrifugation inhibits germination and seedling growth. Moreover, the inhibition of seedling growth increased with the duration of soaking time in water before centrifugation and with the increase in centrifugal force. The force used in their study ranged from 12,000 to $28,000 \mathrm{~g}$ and was applied for 15 to $60 \mathrm{~min}$. When soaked for less than an hour, and then centrifuged for $15 \mathrm{~min}$ at $12,000 \mathrm{~g}$, growth was stunted for $34 \%$ of the seeds, whereas $5 \%$ did not germinate at all. Raghavan (38), experimenting with the sensitive fern (Onoclea sensibilis L.), observed a delay in germination when exposed to hypergravitational forces of low to moderate intensity. Further, he demonstrated that centrifugation induces stress in the seeds which

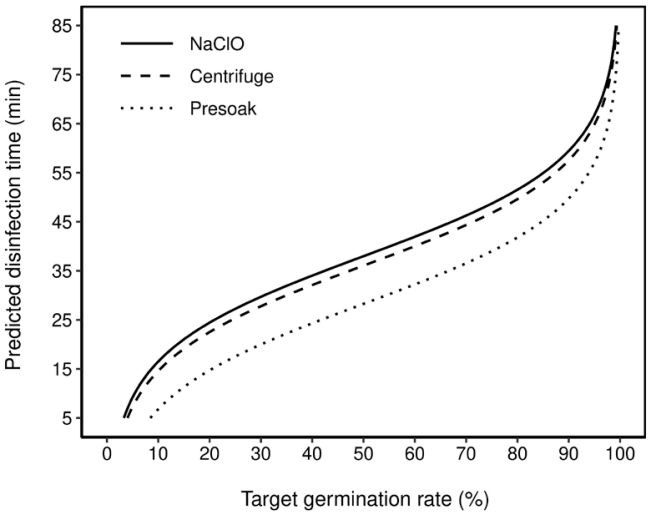

Figure 4. Inverse prediction: The curves predict disinfection/scarification time for a given germination rate, according to fitted model.

equipment, (iv) it adds undue complexity to the process, (v) the test tubes must be moved from the laminar flow cabinet to the centrifuge and back, increasing the risk of infection, and

Table 3. Logistic regression results and parameter estimates for log odds-ratios from Eq. [2]. The regressors are duration of soaking in NaClO and scarification method. The $\mathrm{NaClO}$ method was used as the reference

\begin{tabular}{|c|c|c|c|c|}
\hline Model & -LL & DF & $\boldsymbol{\chi}^{2}$ & \multicolumn{1}{c|}{$\boldsymbol{\chi}^{2}$} \\
\hline Difference & 142.21 & 3 & 284.42 & $<.001$ \\
\hline Full & 145.08 & & \\
\hline Reduced & 287.29 & & \\
\hline $\mathrm{R}^{2}$ & 0.50 & & \\
\hline $\mathrm{N}$ & 432 & & \\
\hline
\end{tabular}

\begin{tabular}{|c|c|c|c|c|c|c|c|}
\hline Term & $\mathbf{N}$ & Estimate & SE & $\mathbf{z}$ & $\boldsymbol{p}>|\mathbf{z}|$ & OR & 95\% C.I. \\
\hline Intercept $\left(\beta_{0}\right)$ & 144 & -3.8866 & 0.447 & -8.694 & $<.001$ & 0.021 & {$[0.008-0.047]$} \\
\hline Duration $\left(\beta_{1}\right)$ & 432 & 0.1023 & 0.009 & 10.790 & $<.001$ & 1.108 & {$[1.089-1.130]$} \\
\hline Centrifuge $\left(\beta_{2}\right)$ & 144 & 0.1969 & 0.363 & 0.543 & 0.587 & {$[0.598-2.492]$} \\
\hline Presoak $\left(\beta_{3}\right)$ & 144 & 0.9947 & 0.373 & 2.664 & 0.008 & 2.704 & {$[1.315-5.709]$} \\
\hline
\end{tabular}

$\mathrm{LL}=\log$ likelihood; $\mathrm{DF}=$ degrees of freedom; $\chi^{2}=$ chi-square; $p=$ probability; $R^{2}=$ ratio of "Difference" to "Reduced" $L L ; \mathrm{N}=$ observations; $\beta_{0}, \beta_{1}, \beta_{2}, \beta_{3}=$ fitted parameters; $S E=$ standard error; $\mathrm{z}=$ estimate divided by its $S E ; O R=$ odds-ratio; C.I. $=95 \%$ confidence interval for $O R$.

results in the synthesis of shock proteins. Another hypothesis is that germination was delayed due to physical seed deformation caused by increased gravity.

Based on our results, the CENTRIFUGE method cannot be recommended for scarification of terrestrial orchid seeds because: (i) the gain in disinfection/scarification time is not statistically significant, (ii) the slight gain in disinfection/ scarification time could be due to the longer rinse time rather than the centrifugation itself, (iii) centrifugation requires more (vii) centrifugation unduly delays germination, although given enough time the proportion of germinated vessels catches up with the other methods.

\subsubsection{PRESOAK method}

The parameter for the PRESOAK method was statistically significant (Table 3). Pretreating the seeds in a 10\% sucrose solution for six hours improves subsequent disinfection in the $0.5 \%$ $\mathrm{NaClO}$ solution. Spores of microorganisms hide in the porous 
surface of the seed (12). The large diversity of microorganisms on the seed surface may reduce susceptibility to disinfecting agents (39). Moreover, because they survived for a long time on a dry surface, microbes exhibit slow growth and reduced metabolism during rewetting, reducing the efficacy of antimicrobial agents. Finally, the specificity of antimicrobial agents varies by species of microorganism. Although sodium hypochlorite $(\mathrm{NaClO})$ is a wide spectrum disinfectant, it has been found inefficient against yeast biofilm (39). For all these reasons, it is helpful to test ways to increase the susceptibility to disinfectants for a wide range of microorganisms.

The sucrose solution causes bacterial and fungal spores to germinate, making them vulnerable to the disinfecting solution (12). Furthermore, the cell growth phase influences the expression and regulation of genes involved in stress tolerance and resistance to biocide (40). The more susceptible growth phase could be the stationary phase or the exponential phase (40-42). In our study, the sucrose was used as a recommended carbohydrate source (16), with the understanding that the optimum carbohydrate source and concentration may vary according to microorganism (bacteria: 41,43,44; fungi: 45,46). Different carbohydrates sources act on different bacterial processes such as germination, elongation or division (43). Similarly, fungal processes such as sporulation, germination and growth are affected (46).

Supposably, one could test different concentrations of sucrose or glucose (e.g., from $0.5 \%$ to $50 \%$ ) to determine if the presence of sugars, even in small quantities, is enough to enhance the disinfection. Additionally, testing different pretreatment times (e.g., 1 to $12 \mathrm{~h}$ ) could help estimate the optimal soaking time in the sugar solution. A key question is whether the additional delay imposed by the presoaking step is worth the enhanced disinfection efficacy.

\subsubsection{Practical considerations}

From a practical standpoint, comparing disinfection/scarification methods for a particular germination tolerance may be more useful than comparing methods across a range of tested times. A working professional in a commercial or research facility may be interested to know what length of disinfection is likely to result in a predetermined germination rate, along with an estimate of certainty of achieving that rate. The problem of inverse prediction is one of solving Eq. (1) for $\mathrm{X}_{1}$, given $\mathrm{P}, \mathrm{X}_{2}$, and $\mathrm{X}_{3}$. For example, if the predetermined tolerance for germination of culture vessels is $90 \%$, the $\mathrm{NaClO}$ method predicts about $59 \mathrm{~min}$ (Fig. 4). The 95\% confidence interval is calculated as 53 to $67 \mathrm{~min}$. The CENTRIFUGE method predicts about $58 \mathrm{~min}$, resulting in a savings of only one minute; the predicted value even lies within the $95 \%$ confidence interval of the $\mathrm{NaClO}$ method. Accordingly, the PRESOAK method will trim about nine minutes off the disinfection time. We think that the added complexity and delay of the CENTRIFUGE and PRESOAK methods hardly justify time savings of only a few minutes. While statistical measures are useful to compare scarification methods, they should be co-evaluated along with other, more practical considerations.

Having said that, we must point out that $A$. laxiflora seeds have a thin testa compared to other terrestrial orchids, so that the addition of a presoaking stage in sucrose solution may not confer a substantial advantage. Perhaps the advantage would be greater on species with a thick testa, such as Himantoglossum robertianum. Indeed, seeds of $H$. robertianum take longer to disinfect $(10,19)$. Also, in our experience, immature capsules of terrestrial orchids used for the technique of "green podding" are harder to disinfect than mature seeds, possibly because microorganisms are protected in the folds of the dusty capsules. In such cases, the PRESOAK method may be worth considering.

\section{Conclusion}

We conclude that (i) the longer the chemical treatment of seeds, the lower the infection rate, and the higher the germination rate, (ii) there is no significant difference in germination rate between the $\mathrm{NaClO}$ and the CENTRIFUGE method, (iii) centrifugation delays germination, although given enough time the proportion of germinated vessels catches up, (iv) the PRESOAK method is superior to the $\mathrm{NaClO}$ method, because the sucrose solution stimulates the germination of spores on the surface of the seeds, making them more susceptible to the disinfectant. However, the savings in disinfection time hardly justify the extra preparation time and complexity. Seeds with thicker testa as well as whole immature capsules could potentially benefit more from pretreatment in sucrose solution.

\section{Acknowledgments}

We thank the Department of Food Science and Technology of the Ionian University for providing the facilities for the experiment and the University of La Rochelle for accepting the internship subject. We are indebted to Mr. Xenophon Haldas for his assistance in locating the native populations that provided seeds. We thank the anonymous reviewers for all suggestions that contributed to the improvement of the manuscript.

\section{Declarations}

\section{Funding}

Not applicable

\section{Conflicts of interest}

On behalf of all authors, the corresponding author states that there is no conflict of interest.

\section{Availability of data and material}

Not applicable

\section{Code availability}

Not applicable

\section{References}

1. Zhang SB, Yang Y, Li J, Qin J, Zhang W, Huang W, Hu H. Physiological diversity of or-chids. Plant Diversity 2018; 40(4): 196-208. 
2. Popova E, Kim HH, Saxena PK, Engelmann F, Pritchard HW. Frozen Beauty: The Cryobiotechnology of Orchid Diversity. Biotechnology Advances 2016; 34(4): 380-403.

3. Delforge P. Orchidées d'Europe, d'Afrique du Nord et du Proche Orient. Paris, Dela-chaux et Niestlé 2016. p 544.

4. Hutchings MJ, Robbirt KM, Roberts DL, Davy AJ. Vulnerability of a specialized pollination mechanism to climate change revealed by a 356-year analysis. Botanical Journal of the Linnean Society 2018; 186(4): 498-509.

5. Hinsley A, De Boer HJ, Fay MF, Gale SW, Gardiner LM, Gunasekara RS, Kumar P, Masters S, Metusala D, Roberts DL, Veldman S, Wong S, Phelps J. A review of the trade in orchids and its implications for conservation. Botanical Journal of the Linnean Society 2018; 186(4): 435-455.

6. Kreziou A, De Boer HJ, Gravendeel B. Harvesting of salep orchids in north-western Greece continues to threaten natural populations. Oryx 2016; 50(3): 393-396.

7. Masters S, van Andel T, De Boer HJ, Heijungs R, Gravendeel B. Patent analysis as a novel method for exploring commercial interest in wild harvested species. Biological Conservation 2020; 243(June 2019): 108454.

8. Gerakis A, Haldas X, Giannakoulias M. Anacamptis palustris subsp. robusta (Orchidaceae): a new record to the flora of Cephalonia, Greece. J Eur Orch 2016; 48(1): 11-18.

9. Hirth M. A long-term survey of orchids on the small Greek Island Agathonisi from 1994 to 2013. J Eur Orch 2016; 48(1): 37-52.

10. Katsalirou E, Gerakis A, Haldas X, Deconninck G. Optimal disinfection times for seeds of mediterranean orchids propagated on nutrient media. European Journal of Environmental Sciences 2017; 7(2): 119-124.

11. Rasmussen HN. Terrestrial orchids: From seed to mycotrophic plant. Cambridge, Cambridge University Press 1995. p 444.

12. Jevšnik T, Luthar Z. Successful disinfection protocol for orchid seeds and influence of gelling agent on germination and growth. Acta Agriculturae Slovenica 2015; 105(1): 95-102.

13. Ponert J, Vosolsobě S, Kmecová K, Lipavská H. European orchid cultivation - from seed to mature plant. European Journal of Environmental Sciences 2012; 1(2): 95-107.

14. Chen Y, Goodale UM, Fan XL, Gao JY. Asymbiotic seed germination and in vitro seedling development of Paphiopedilum spicerianum: An orchid with an extremely small population in China. Global Ecology and Conservation 2015; 3: 367-378.

15. Godo T, Komori M, Nakaoki E. Germination of mature seeds of Calanthe tricarinata Lindl., an endangered terrestrial orchid, by asymbiotic culture in vitro. In Vitro Cellular \& Developmental Biology - Plant 2010; 46: 323-328.

16. Hicks AJ. Asymbiotic Technique of Orchid Seed Germination. The Orchid Seedbank Project, USA, Arizona, Chandler 2000. p 134.

17. Malmgren S. On the origin of Ophrys species. J. of the Hardy Orchid Society 2004; 1(3): 74-81.
18. Malmgren S, Nyström H. Orchid propagation 2020. Available at http://www.lidaforsgarden.com/orchids/engelsk. htm. Accessed 17 Aug 2020.

19. Katsalirou E, Gerakis A, Haldas X. Optimal scarification times for seeds of two Mediterranean orchids. European Journal of Environmental Sciences 2019; 9(1): 47-52.

20. Delforge P. Orchids of Europe, North Africa and the Middle East. Paris, Delachaux et Niestlé 2005. p 640.

21. Garbaye J. La symbiose mycorhizienne : une association entre les plantes et les champignons. Versailles, Editions Quae 2013. p 284.

22. Marschner H. Mineral nutrition of higher plants. CA, San Diego, Academic Press 1995. p 889.

23. Bakar B, Abdul Latip M, Azlan Gansau J. Asymbiotic germination and seedling development of dimorphics lowii (Orchidaceae). Asian Journal of Plant Biology 2014; 2(1): $18-27$.

24. Lee YI, Chen MC, Huang CY. Effect of medium composition on asymbiotic seed germination of five Phalaenopsis species. Acta Horticulturae 2010; 878: 225-230.

25. Lee YI, Yeung ECT. Orchid Propagation: From Laboratories to Greenhouses-Methods and Protocols. Lee YI, Yeung ECT (Eds) NY, New York, Springer New York 2018. p 516.

26. El Sanharawi M, Naudet F. Comprendre la régression logistique. Journal Français d'Ophtalmologie 2013; 36(8): 710-715.

27. Jaeger TF. Categorical data analysis: Away from ANOVAs (transformation or not) and towards logit mixed models. Journal of Memory and Language 2008; 59(4): 434-446.

28. Rouvière L. Régression logistique avec R. Université Rennes 2, UFR Sciences Sociales 2015. Available at https:// perso.univ-rennes2.fr/system/files/users/rouviere_1/poly_ logistique_web.pdf. Accessed 17 Aug 2020.

29. R Core Team. R: A language and environment for statistical computing. Austria, Vienna, R Foundation for Statistical Computing 2016. URL http://www.R-project.org/

30. Zeng S, Wu K, Teixeira da Silva JA, Zhang J, Chen Z, Xia N, Duan J. Asymbiotic seed germination, seedling development and reintroduction of Paphiopedilum wardii Sumerh., an endangered terrestrial orchid. Scientia Horticulturae 2012; 138: 198-209.

31. Kauth PJ, Dutra D, Johnson TR, Stewart SL, Kane ME, Vendrame W. Techniques and Applications of In Vitro Orchid Seed Germination. In Floriculture, Ornamental and Plant Biotechnology. Teixeira da Silva JA (Ed) UK, Global Science Books Ltd 2008; 375-391.

32. Bozdemir H, Çiğ A, Türkoğlu N. Effects of different concentrations of carbohydrate forms on Orchis sancta L. Propagation in vitro. Applied Ecology and Environmental Research 2018; 16(4): 4849-4864.

33. Nykiforuk CL, Johnson-Flanagan AM. Germination and early seedling development under low temperature in canola. Crop Science 1994; 34: 1047-1054.

34. Gray SW, Edwards BF. Effects of centrifugal forces on 
growth and form of coleoptile of wheat. Journal of Cellular and Comparative Physiology 1995; 46(1): 97-125.

35. Kostoff $\mathrm{D}$. The effect of centrifuging upon the germinated seeds from various plants. Cytologia 1938; 8(3-4): 420442.

36. Siegel SM, Renwick G, Daly O, Giumarro C, Davis G, Halpern L. The survival capabilities and the performance of earth organisms in simulated extraterrestrial environments. In Current Aspects of Exobiology. Mamikunian G, Briggs MH (Eds) Oxford, Permagon Press 1965; 119-178.

37. Norris Jr WE, Wikinson MN. The effects of centrifugation and hydrostatic pressure on Avena germination and seedling development. Zeitschrift Für Pflanzenphysiologie 1980; 98(4): 311-319.

38. Raghavan V. Developmental Biology of Fern Gametophytes. Cambridge, Cambridge University Press 1989. p 361.

39. Otter JA, Vickery K, Walker JT, deLancey Pulcini E, Stoodley P, Goldenberg SD, Salkeld JAG, Chewins J, Yezli S, Edgeworth JD. Surface-attached cells, biofilms and biocide susceptibility: Implications for hospital cleaning and disinfection. Journal of Hospital Infection 2015; 89(1): 16-27.

40. Randhawa V, Thakkar M, Wei L. Effect of algal growth phase on Aureococcus anopha-gefferens susceptibility to hydrogen peroxide. Aquatic Toxicology 2013; 142-143: 230-238.

41. Ahn SJ, Qu MD, Roberts E, Burne RA, Rice KC. Identification of the Streptococcus mutans LytST two-component regulon reveals its contribution to oxidative stress tolerance. BMC Microbiology 2012; 12(1): 187.

42. Evans DJ, Brown MRW, Allison DG, Gilbert P. Susceptibility of bacterial biofilms to tobramycin: Role of specific growth rate and phase in the division cycle. Journal of Antimicrobial Chemotherapy 1990; 25(4): 585-591.

43. Hyatt MT, Levinson HS. Effect of Sugars and Other Carbon Compounds on Germination and Postgerminative Development of Bacillus Megaterium Spores. Journal of Bacteriology 1964; 88(5): 1403-1415.

44. Tehri N, Kumar N, Yadav A, Raghu HV, Singh NA. Sugars mediated germination in spores of Bacillus megaterium. International Journal of Microbiology Research 2018; 10(3): 1058-1061.

45. Anusha A, Mahesh YS, Mesta RK, Basavarajappa MP, Patil SN, Babu AG. Effect of different sugar solutions, temperature and relative humidity on uredospore germination of Cerotelium fici (Cast.) Arth. causing rust disease on fig (Ficus carica Linn.). International Journal of Current Microbiology and Applied Sciences 2018; 7(11):3558-3565.

46. Grover RK, Bansal RD. The effect of carbohydrates on growth and sporulation of Aspergillus flavus and their carry over for subsequent spore germination. Sydowia 1967; 23: $169-180$. 